\title{
PUBLIC RESEARCH AND INNOVATION INFRASTRUCTURE OF THE REPUBLIC OF MOLDOVA: CHALLENGES AND OPPORTUNITIES
}

\author{
Igor Cojocaru $^{1}$, Alfreda Rosca ${ }^{1}$, Andrei Rusu ${ }^{1,2}$ and Mihail Guzun ${ }^{1}$
}

\begin{abstract}
Currently the science and innovation area of the Republic of Moldova is undergoing an extensive process of transformation aiming to increase the effectiveness, to facilitate the inclusion of national science into the ERA. Taking into account that the European integration is a major priority for the Republic of Moldova, the public research and innovation sector should comply with the best European and international practices. In this regard, the Republic of Moldova developed Research Strategy till 2020 that provides enhancing the quality and efficiency of administrative processes for implementation of the best innovative measures aiming at the development of human, institutional and infrastructure capabilities. In actual conditions, it is important to align with the European practices, in special with the policies promoted by the European Strategy Forum on Research Infrastructures (ESFRI), which has a key role in policy-making on research infrastructures in Europe, the European Open Science Cloud (EOSC) - a cloud for research data in Europe, background, policy information, events and publications, ERRIS (Engage in the Romanian Research Infrastructures System) - platform for research infrastructures, research \& technological services, etc. Nowadays, for science and innovation area of the Republic of Moldova is necessary to build tools for fostering the continuous dialogue between science, Government, society, stimulating the private sector access to research infrastructure, scientific laboratories and results, creating the appropriate conditions for facilitation the process of actual challenges turning into opportunities.
\end{abstract}

\section{Introduction}

Currently the research and innovation area of the Republic of Moldova is undergoing an extensive process of transformation aiming to increase the effectiveness and facilitate the inclusion of national science into the European Research Area (ERA). Taking into account that the European integration is a major priority, the public research and innovation sector should comply with the best European and international practices. In this regard in the Republic of Moldova was developed the Research Strategy till 2020 that provides enhancing the quality and efficiency of administrative processes trough implementation of the best innovative measures aiming at the development of human, institutional and infrastructure capabilities. The governmental documents of the Republic of Moldova provide roadmap of science and innovation sector elaboration, one of the main goals of which is the national research infrastructure upgrading by 2020, the connection of national science infrastructure to the European networks, including the efficient use of e-infrastructures and information resources, implementation of efficient technologies and setting-up a favorable environment to dissemination, absorption and exploitation of scientific information in society.

\footnotetext{
1 Information Society Development Institute, str. Academiei 5A, Chisinau, Republic of Moldova, \{igor.cojocaru,alfreda.rosca,andrei.rusu,mihail.guzun\}@idsi.md, https://www.idsi.md/

${ }^{2}$ Ovidius Univercity of Constanta, bd. Mamaia 124, Constanta, Romania, agrusu@univ-ovidius.ro, http://math.univovidius.ro/
} 
The purpose of the article is to elucidate the situation in the research and innovation infrastructure of the Republic of Moldova, to underline the needs of this sector developing through innovative informational tools implementation, to select the most acceptable practices for science infrastructure safeguarding and aligning to the best European experiences.

Nowadays for research and innovation area of the Republic of Moldova is necessary to build tools for fostering the continuous dialogue between science, Government, society, private sector, for access facilitating to research infrastructure, scientific laboratories and results. In this connection, a good advice for the Republic of Moldova can be the next phrase „The state must be in possession of the organizational and operational capabilities needed to react to the quickly changing challenges of our times while effectively pursuing the national interest in the face of conflicting regional and global agendas" [16]. Many provocations are arising for Moldovan research area, that's why the Government, responsible entities, everybody should rapidly adapt to the evolving regional and global challenges and contribute to their turning into opportunities.

\section{Defining the term "infrastructure", including "e-infrastructure"}

Considering that these notions in specialized sources are differently explained, there is no a unique understanding of infrastructure and e-infrastructure, these terms are viewed and analyzed from different points of view appeared the need of their clarification for the purpose of better understanding of the subject.

The Science and Innovation Code of the Republic of Moldova, approved in 2004, qualifies the infrastructure of research as the organizations that carry out scientific and innovation activities: Academy of Sciences, other institutions performing science and innovation, financial ones, business incubators, innovation parks (scientific, techno-scientific and technological), enterprises and other specialized organizations [19, art. 25]. The Oxford Dictionary describes infrastructure as basic physical and organizational structures and facilities (e.g. buildings, roads, power supplies) needed for the operation of a society or enterprise [18]. In the American Heritage Dictionary infrastructure is an underlying base or foundation especially for an organization or system; the basic facilities, services, and installations needed for the community or society functioning, such as transportation and communications systems, water and power lines, and public institutions including schools, post offices, etc [14]. In Cambridge Advanced Learner's Dictionary infrastructure is described as

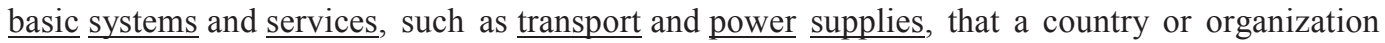
uses in order to work effectively [2]. The International Standard ISO 9000: 2015 "Quality Management Systems - Fundamentals and Vocabulary" defines infrastructure as a system of facilities, equipment and services needed for the operation of an organization [22].

As an umbrella for all infrastructures in the field of scientific research, e-infrastructure is the basic element that helps bring together researchers from different corners of the globe, allows access to scientific data and tools in high-performance laboratories around the world, enables international collaborative research, provides unique services to users from different countries, as well as opens opportunities for young people attracting into science. E-infrastructure is an environment where resources (hardware, software and content) can be easily accessed. It provides the scientific community with a 24-hour digital resource market, regardless of location, and serves as a unique tool for collaborative applications developing [5]. Viewed by the UK Research Council $e$ infrastructure refers to a combination and interconnection of digital technologies (hardware and software), resources (data, services, and digital libraries), communications (protocols, access rights 
and networks), researchers and organizational structures needed to support modern research, based on international collaboration [7].

E-infrastructure plays an increasingly active role in knowledge advancement, contributes to the creation of innovative environment. It is at the heart of knowledge triangle: research, education and innovation. The widespread use of e-infrastructure is an important step towards digital differences and brain drain reducing.

\section{Research infrastructure in the Republic of Moldova}

Throughout the history of science, the number of research organizations in the Republic of Moldova varied numerically in different times. Thus, nine research institutes were active in 1960, in 1970 66, 1985 - 107, 2004 - 101. In 2017, there were nine research institutes of the Academy of Sciences of Moldova, 33 scientific organizations from different branches, 12 accredited universities, 2 museums, 3 science and technology parks and 7 innovation incubators [11].

At the end of 2014 in the Republic of Moldova was approved the Research and Development Strategy until 2020. One of the basic objectives of the strategy is human, institutional and infrastructure capacities development [13, p. 28]. According to its provisions, this major task is to be accomplished through innovative tools implementation for private sector access facilitating to research infrastructure, scientific laboratories, fostering continuous dialogue between science and society, knowledge disseminating and research results capitalizing [13, p. 51].

For these purposes and in the line with European and international performance standards in the Republic of Moldova in 2010 the knowledge network ACADEMICA was designed and developed [4]. Its main objective is to provide a computerized infrastructure for accessing and sharing scientific and technological information to research institutions and universities, to increase the capacities at a new technological level in order to meet the challenges of implementing the European practices, in special the concept of Open Science. Exploiting the opportunities offered by ACADEMICA e-infrastructure, including interconnection with researchers from other countries, help to strengthen national teams in interdisciplinary project proposals development and joint participation in HORIZON 2020 Program calls. Based on Principles for Open Scholarly Infrastructures and in line with the Amsterdam Open Call for Open Science Action (April 2016), ACADEMICA e-infrastructure will be expanded in the nearest future.

An important public institution in the Republic of Moldova is the Research and Educational Networking Association of Moldova (RENAM), which represent an interoperable collaboration platform that contributes to the convergence of universities and research institutions electronic infrastructure. The principal purpose of its activities is a constant development of communication and information infrastructure of scientific and educational Moldovan communities. [1].

Thanks to the EU projects, several universities of the Republic of Moldova have created their institutional repositories. The software solutions are open-source, namely, DSpace [12]. In addition to the institutional repositories, there is a national repository, created by the Information Society Development Institute, named National Bibliometric Instrument (IBN) [15], where scientific publications are stored. Public scientific libraries in the Republic of Moldova are equipped with computers connected to the Internet, some of them provide access to other electronic resources through collaborative agreements with international organizations (Research4Life) [20]. 
In the period 2009-2012 Moldovan researchers together with 19 partners from 10 countries implemented the SEERA-EI (South East Europe Space for e-Infrastructure Research Area) project [21]. The main objective was to develop and strengthen the coordination and cooperation of einfrastructure programs in the South East Europe region. This project has paved the way for sustainable regional co-operation. Within the project was developed the "Common Regional Vision and e-Infrastructure Strategy", which sets out a mutual strategy for e-infrastructure development in the South East Europe region. The elaborated Memorandum provides for a fiber backbone network to be set up in the South East Europe region by 2020. The SEERA-EI and other related regional projects focused on e-infrastructure development issues have enabled the foundation of modern electronic infrastructure and related services in the Republic of Moldova. The permanent upgrading of e-infrastructure components is in the line with the Europe's overall objective - accelerating the development of the information society in Europe, ensuring its availability for all the communities.

In this regard, the Information Society Development Institute of the Republic of Moldova is working on innovative tools creation for research system monitoring and evaluating, indicators of scientific production measuring, system mapping via innovative methodologies for information studying and processing. The Information Society Development Institute performs activities oriented:

- $\quad$ on shareable e-infrastructure development for a better use of the services provided by local administration, European e-infrastructures;

- $\quad$ on Open Science principles implementation through software tools development, such as National Bibliometric Instrument (ibn.idsi.md), Expert Online (expert.idsi.md),

- $\quad$ on acquisition and setting-up of equipment for digital identity (IdP, SP) management, mobile access (EduRoam),

- $\quad$ on consequently provision of secure, reliable access to systems and services available in ACADEMICA and other European e-infrastructures,

- $\quad$ on establishing, together with RENAM (the national NREN), a national federation of research identity providers.

\section{European research infrastructure policy}

The European Union undertook several initiatives to support the advancement of research infrastructures and e-infrastructure, in particular as an important tool for the development of scientific research in general. The European Strategic Research Infrastructure Forum (ESFRI) [10] determines the overall policy on research infrastructure in Europe. ESFRI's mission is to facilitate multilateral initiatives for better use and development of research infrastructures at EU and international level. ESFRI develops recommendations for ensuring equal access to European resources. Open access to advanced digital services, scientific tools, data, knowledge and expertise that researchers need to collaborate and achieve excellence in science and innovation is a central goal of European policy. The EU believes that the whole community must be engaged in the governance, management and conservation of these resources for the people benefit.

In order to solve some strategic issues regarding the development of e-infrastructure components, the European Commission established in 2003 a special e-Infrastructure Reflection Group (e-IRG) 
[9]. The e-IRG vision is an open and innovative e-infrastructure that offers flexible cooperation and optimal use of available electronic resources by international communities. E-IRG coordinates panEuropean initiatives and joint electronic infrastructure development projects for research and innovation in Europe. The European Union recognizes the decisive role of e-infrastructure in achieving scientific excellence, its major contribution in attaining the objectives of Digital Agenda for Europe and vision for the European Research Area. Electronic infrastructures enhance research creativity and efficiency; reduce the gap between developed and less developed countries.

In this regard, was analyzed the innovative informational platform ERRIS (Engage in the Romanian Research Infrastructure System), a register of research infrastructure in Romania [24]. ERRIS was launched in mid-2015 in order to increase visibility and facilitate access to Romanian research infrastructure. This platform has been developed to support and promote Romanian public / private research infrastructure, to stimulate collaboration and participation in national and international networks. The platform makes research more open and transparent, contributes to the effective use of available scientific equipment, increase the visibility and facilitate access to it. The ERRIS platform is considered a "facebook of things" of Romanian research community. Currently, ERRIS brings together 1.611 infrastructures with 8.331 research services, 140 technological services and 22.203 equipments (situation 10.03.2018). So, this example from an EU member country is necessary to follow in the Republic of Moldova and today the Information Society Development Institute is taking steps for the creation a similar "facebook" of the Moldovan research infrastructure.

\section{Research infrastructure components}

The Manual ISO 9001:2015 Quality Management System stipulates that organization is responsible for planning, providing and maintaining the resources needed to achieve product and process conformance, including buildings, workspace and associated utilities, process equipment (hardware and software) and supporting services [23, see 7.1.5]. Thus, the infrastructure includes:

- buildings and associated utilities,

- $\quad$ equipment, involving hardware and software,

- transport resources,

- $\quad$ information and communication technologies.

According to the Frascati Manual (edition 2015) [17, p. 31] for the area of science and innovation, the basic components of infrastructure are:

- $\quad$ lands and buildings,

- $\quad$ machinery and equipment,

- $\quad$ capitalized computer software,

- $\quad$ other intellectual property products. 


\section{Research infrastructure maintaining and developing in the Republic of Moldova}

In order to align with the principles of Open Science [6], the most important goal of the next European Program Framework, the Information Society Development Institute coordinates its activities with local governmental organizations, with different international institutions, tries to implement the best practices. The institute is going to create an online platform of infrastructure in the field of science and innovation. The beneficiaries will be the scientific community (researchers, professors, $\mathrm{PhD}$ students, students), those responsible for managing RDI activities, experts, institutions involved in creation, archiving and dissemination of digital scientific content, organizations responsible for policy implementation, business sector. The society will benefit from open access to scientific heritage of the country; the results will be used in bibliometric and webometric analysis. As a result of data collection, administration, processing and interpretation services, it will be possible to generate: specific lists, reports, organizational charts, diagrams and graphs, statistical and comparative data. More quality data available to policy makers in the Republic of Moldova may lead to a better management of its research.

For Moldovan researchers' cohesive actions and e-infrastructure developing are important, the services provided by:

- $\quad$ LEAF - Identity Federation for Research and Education Institutions of the Republic of Moldova,

- EDUROAM - unlimited Wi-Fi access to scientific and educational community around the world,

- $\quad$ eduGAIN - unlocking global collaboration in education and research, Federation as a Service - federative link to resources and data,

- $\quad$ GEANT Cloud Services - services that support cloud-based collaboration,

- $\quad$ GEANT Open - Facilitating Open Collaboration Globally,

- $\quad$ GEANT VPN Services - service for private and secure connections designed to create global cross-border research teams,

- $\quad$ perfSONAR - real-time monitoring of multiple performance ranges,

- $\quad$ Performance Enhancement Response Team - support service within the community to achieve maximum network performance,

- $\quad$ eduCONF - improving access to video conferences,

- $\quad$ eduOER - support for accessing media content from various repositories,

- $\quad$ RENum.net - interconnecting different ways to dial for real-time connections.

These technologies mainly deal with e-infrastructure, so, as a conclusion, a better e-infrastructure management based on innovative e-services and e-tools is a must do. 
The research infrastructure platform, which will be elaborated, will facilitate integration of scientific community into the European information system of databases, serving as a support in management activities. The mapping of existing organizations, equipment, products and research services in the Republic of Moldova will contribute to:

- $\quad$ visibility and transparency increasing;

- $\quad$ science governance facilitating;

- $\quad$ quality and efficiency of science management enhancing;

- $\quad$ use and share of scientific equipment rising;

- cooperation at national and international level stimulating;

- $\quad$ new partnerships between research entities and private sector establishing;

- $\quad$ research institutions competitiveness increasing;

- $\quad$ expertise process facilitating;

- $\quad$ an overview of national research ecosystem providing;

- $\quad$ an engine of internationalization and promotion of research serving;

- $\quad$ governance and management science system strengthening;

- $\quad$ role of science in society increasing.

\section{E-Government for research area}

The achievements in the information technologies have changed the communication process between citizens, science and Government. The efforts made by the Moldovan Government to accelerate the development of complex e-services with reference to research e-infrastructure have the goal to ensure effectiveness of e-services and reduce the administrative burden. In order to enhance the quality and efficiency of administrative processes and public services in the Republic of Moldova was created the institution "E-Government Center". The aim of this organization is to improve the governance quality through a wide application of information and communication technologies in all areas. For security assuring in the field of e-infrastructure and for important strategic relationships building was developed the Cyber Security Center CERT-GOV-MD. Its mission is to increase the capability of M-Cloud beneficiaries, public administration authorities, Moldova's critical information service providers, to respond to vulnerabilities, threats, and information security incidents in order to protect ICT infrastructure and preserve trust in governmental information system [3].

An important role plays the Platform of Electronic Services that offer citizens the possibility to authenticate to government and public authorities' e-services, similar to national federation of identity providers LEAF, with the aim to unify the scheme of access to any e-services [8]. Another e-service, offered via e-government is the MPay, which allows paying in a secured manner. 


\section{Conclusions}

The officials of the Republic of Moldova have to recognize that a strategic role in increasing the country's competitiveness, in ascending economic prosperity, lies in the area of science, technological development, and innovations implementation. To achieve the goal of better competitiveness the civil society of the Republic of Moldova and its elected representatives should follow the best practice of EU countries. In order to maintain and develop the infrastructure in the Republic of Moldova, essential support from the state is required, more active involvement in realization of as many international projects as possible, supporting the performance, endowing science with modern equipment, taking over the best technologies. In the area of informational support for science and innovation, the best things that can be done are the next concrete examples:

- $\quad$ to continue efforts to get a platform of the available research infrastructure,

- $\quad$ to establish a functional and widely used federation of identity providers and service providers,

- based on the federation of identity providers to support creation of virtual research teams, which involve researchers from the Republic of Moldova,

- $\quad$ to wider the use of services based on GEANT network,

- $\quad$ to facilitate the concept of open science, including the concept of open data in Government's policy regarding research.

The maintenance and improvement of research infrastructure with permanent Government support and efficient coordination must become a primary task in the country's policy. This desideratum needs to be developed around strategic areas, necessary for state, and synergistically correlated, so as to strengthen the infrastructure, maintain and advance the tendency of integration in the European Union. Under the current circumstances, through information innovative tools it is important to create a simulative and favorable environment for private investment in science, for dialogue and cooperation encouraging between politics, administration, civil society and citizen, and promoting efficient public-private partnerships.

Acknowledgments. Special thanks to the SCIFORM national project (15.817.06.13A) and E-IDSM research project (18.50.07.10A/PS) that have partially supported research on this paper.

\section{References}

[1] BOGATENCOV, P., SECRIERU G., TIGHINEANU I., E-Infrastructura RENAM platforma interoperabilă de colaborare, resurse şi servicii informaţionale în cercetare şi educaţie, Akademos, nr. 2 (45), 2017, https://ibn.idsi.md/ro/vizualizare_articol/53338

[2] CAMBRIDGE UNIVERSITY PRESS, Cambridge online dictionary, Cambridge Dictionary: English Dictionary, http://dictionary.cambridge.org/dictionary/english/infrastructure? $\mathrm{a}=$ british (accessed 26.10.17)

[3] CERT-GOV-MD, Cyber security center, http://cert.gov.md/ (accessed 15.10.17) 
[4] COJOCARU, I., Knowledge Networking - a Promising Tool for Developing Moldova's R\&D, in: Proceedings of the International Conference on Intelligent Information Systems IIS2013, August 20-23, 2013, Chisinau, Republic of Moldova, https://idsi.md/files/file/publicatii/2013/Knowledge\%20networking_a\%20promising\%20tool $\% 20$ for\%20developing\%20Moldovas\%20RD\%20protential.pdf

[5] CORDIS, Community Research and Development Information Service, http://cordis.europa .eu/ictresults/home_en.html (accessed 18.10.17)

[6] CREATIVE COMMONS, Science Commons, http://sciencecommons.org/resources/ readingroom/principles-for-open-science/ (accessed 20.11.17)

[7] DEPARTMENT for Business Innovation and Skills, Delivering the UK's e-Infrastructure for Research and Innovation, Technical Report, UK Research Councils, 2010, http://www.rcuk.ac.uk/documents/research/esci/e-infrastructurereviewreport-pdf/

[8] EGC, Portalul serviciilor electronice, http:/e-services.md/ (accessed 10.12.17)

[9] E-IRG, E-Infrastructure Reflection Group, http://e-irg.eu/ (accessed 22.11.17)

[10] EUROPEAN COMMISION, European Research Infrastructures, http://ec.europa.eu/research/ infrastructures/index_en.cfm?pg=esfri (accessed 28.11.17)

[11] DUCA, Gh., Știinţa şi inovarea în Republica Moldova: istorie şi actualitate, Akademos, 1, 2017, 92-103, http://www.akademos.asm.md/files/92_104_Stiinta\%20si\%20inovarea\%20\% D0\%Ben\%20Republica\%20Moldova_istorie\%20si\%20actualitate.pdf

[12] DURASPACE, http://www.dspace.org/ (accessed 15.12.17)

[13] GOVERMENT of the Republic of Moldova, Strategia de cercetare-dezvoltare a Republicii Moldova până în 2020, Goverment of the Republic of Moldova, Chisinau, 2013, http://www.asm.md/galerie/2013_11_25_Str_CD-2020_FINAL.pdf

[14] Houghton Mifflin Harcourt, The American Heritage Dictionary of English Language, Houghton Mifflin Publisher, 2015, https://www.ahdictionary.com/word/search.html?q= infrastructure (accessed 12.10.17)

[15] IDSI, Instrumentul bibliometric national, http://ibn.idsi.md/ (accessed 12.11.17)

[16] KASER, T. (ed)., Good State and Governance Report 2015, National University of Public Service, 2015, Budapest, Hungary, http://archiv.en.uni-nke.hu/uploads/media_items/goodstate-and-governance-report-2015.original.pdf

[17] OECD, Frascati Manual 2015: Guidelines for Collecting and Reporting Data on Research and Experimental Development, OECD Publishing, Paris, http://dx.doi.org/10.1787/978926 4239012-en

[18] OED, English Oxford Living Dictionaries, Oxford University Press, UK, https://en.oxforddictionaries.com/definition/us/infrastructure (accessed 14.10.17) 
[19] PARLIAMENT of the Republic of Moldova, Cod nr. 259 cu privire la știință și inovare al Republicii Moldova, Monitorul Oficial, nr. 125-129, 30.07.2004, http://lex.justice.md/index. php?action=view \&view $=$ doc\&id=286236

[20] RESEARCH4LIFE, http://www.research4life.org/ (accessed 05.12.17)

[21] SEERA-EI Project, Deliverable D4.1a. SEERA-EI-Interim Report-b-2011-7-22, 63 p.

[22] Technical Committee ISO/TC 176, ISO 9000:2015 Quality management systems Fundamentals and vocabulary, Standard, International Organization for Standardization, Geneva, CH, https://www.iso.org/obp/ui/\#iso:std:iso:9000:ed-4:v1:en

[23] Technical Committee ISO/TC 176, ISO 9001:2015 - Quality management systems Requirements, Standard, International Organization for Standardization, Geneva, $\mathrm{CH}$, https://www.iso.org/obp/ui/\#iso:std:iso:9001:ed-5:v1:en

[24] UEFISCDI, Engage in the Romanian Research Infrastructure System, http://www.erris.gov.ro/index.php (accessed 15.12.17) 